\title{
Granulosa Cell Apoptosis in the Ovarian Follicle-A Changing View
}

\author{
Sheena L. P. Regan ${ }^{1 *}$, Phil G. Knight', John L. Yovich ${ }^{1,3}$, Yee Leung ${ }^{4}$, Frank Arfuso' \\ and Arun Dharmarajan ${ }^{1}$ \\ ${ }^{1}$ Stem Cell and Cancer Biology Laboratory, School of Pharmacy and Biomedical Sciences, Curtin Health Innovation \\ Research Institute, Curtin University, Perth, WA, Australia, ${ }^{2}$ School of Biological Sciences, University of Reading, Reading, \\ United Kingdom, ${ }^{3}$ PIVET Medical Centre, Perth, WA, Australia, ${ }^{4}$ Western Australian Gynaecologic Cancer Service, King \\ Edward Memorial Hospital for Women, Perth, WA, Australia
}

OPEN ACCESS

Edited by: David Gregory Mottershead, Keele University, United Kingdom

Reviewed by: Abir Mukherjee, Royal Veterinary College, United Kingdom Livio Casarini, University of Modena and Reggio Emilia, Italy Jing $X u$,

Oregon Health \& Science University, United States

*Correspondence:

Sheena L. P. Regan sheenaregan@aapt.net.au

Specialty section: This article was submitted to Reproduction, a section of the journal

Frontiers in Endocrinology

Received: 02 November 2017 Accepted: 12 February 2018

Published: 02 March 2018

Citation:

Regan SLP, Knight PG, Yovich JL, Leung Y, Arfuso F and Dharmarajan A

(2018) Granulosa Cell Apoptosis in the Ovarian Follicle-A Changing View.

Front. Endocrinol. 9:61. doi: 10.3389/fendo.2018.00061
Recent studies challenge the previous view that apoptosis within the granulosa cells of the maturing ovarian follicle is a reflection of aging and consequently a marker for poor quality of the contained oocyte. On the contrary, apoptosis within the granulosa cells is an integral part of normal development and has limited predictive capability regarding oocyte quality or the ensuing pregnancy rate in in vitro fertilization programs. This review article covers our revised understanding of the process of apoptosis within the ovarian follicle, its three phenotypes, the major signaling pathways underlying apoptosis as well as the associated mitochondrial pathways.

Keywords: apoptosis signaling, ovarian reserve, aging effects, fertility preservation, receptor of follicle stimulating hormone, bone morphogenetic proteins, mitogenic growth

\section{INTRODUCTION}

Pregnancy rate and oocyte quality have been linked to the incidence of apoptosis in women receiving in vitro fertilization (IVF) treatment (1). Poor prognosis patients (such as older women) had a greater incidence of apoptosis (number of pyknotic bodies), while follicles yielding oocytes that fertilized had lower levels of granulosa cell apoptosis $(1,2)$. Several growth factors and hormones are antiapoptotic, such as bone morphogenetic proteins (BMPs), follicle stimulating hormone (FSH), luteinizing hormone (LH), and estrogen. Recent studies from our group reported that granulosa cell expression of the receptors (R) of FSH (FSHR), BMP (BMPR1B), and LH (LHR) are reduced and dysregulated in older women; yet in the same cohort of women, granulosa cell apoptosis was highest in the younger rather than the older women (3-5). Different techniques have been applied historically to determine the level of apoptosis. In the light of recent reports for apoptosis analysis, there arises the question of whether apoptosis is an accurate measure for the interpretation of oocyte quality.

\section{NECROSIS AND APOPTOSIS: MORPHOLOGICAL FEATURES}

Necrosis results from cellular exposure to a toxin or destructive agent which causes swelling and disruption to the cell's organelles, leading to an irreversible breakdown of the cell's membranes and the scattering of the cytoplasmic and nuclear contents (6). This leads to a marked inflammatory response by the body. However, apoptosis is caused by several distinctive signaling pathways, which culminate in shrinkage of the cell, cytoplasmic blebbing, and compartmentalization of organelles (Figure 1) (7-9). Characteristically there is no consequent inflammatory response. Although the cell membranes lose integrity, they fold and encapsulate (blebbing) to prevent the contents from affecting neighboring cells, a feature which is not observed in necrotic granulosa cells (10). Apoptotic cells 


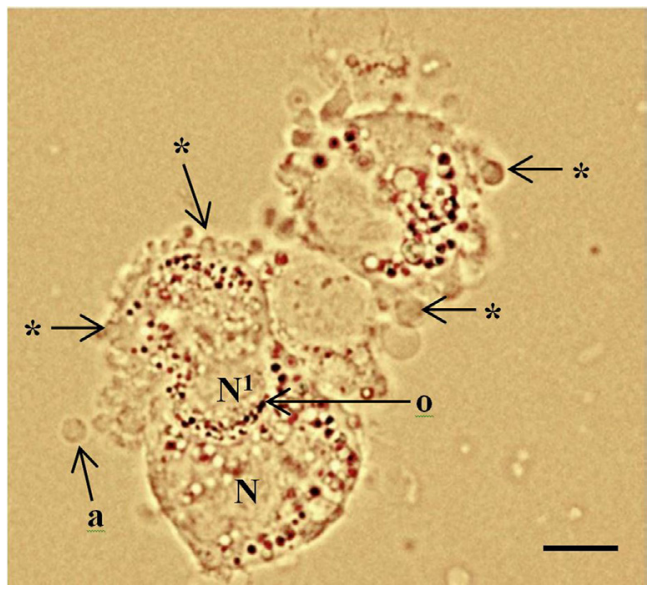

FIGURE 1 | Periluteal granulosa cells and cell morphology. Human granulosa cells were collected from a $15 \mathrm{~mm}$ follicle during an in vitro fertilization cycle at the time of oocyte collection. The granulosa cells are peri-luteal cells; however, the cytoplasm is still relatively compact compared to granulosa cells collected from ovulatory follicles (5). The granulosa cells have dense clustering of organelles around the large round nucleus $(\mathrm{N})$. The cytoplasm appears granular during the late stages of follicular phase; large lipid droplets contain hormones. Cytoplasmic extrusions or blebbing, which indicates late apoptosis are shown (*); apoptotic bodies (a); organelles (o) clustered around the nucleus. Healthy granulosa cell $(\mathrm{N})$ without blebbing is engulfing a neighboring apoptotic granulosa cell nucleus (N1) via phagocytosis (10). Bar $5 \mu \mathrm{m}$.

typically have pyknotic, crescent-shaped or rounded dark bodies of dense DNA, fragmented into smaller sections. However, the majority of pyknotic cells in the middle layers of the membrana granulosa had been consumed by adjacent healthy cells.

Necrosis and apoptosis both culminate in cell death of the granulosa cell, and nucleic dyes that stain DNA material are commonly used to indicate the vitality of the cell membranes (11). Uniquely, the apoptotic granulosa cell will continue to synthesize steroid hormones until the mitochondrial membranes are disrupted. Functioning apoptotic granulosa cells undergo reorganization of the cell cytoplasm, creating blebs of non-cytoplasmic organelles at the periphery; and mitochondria, Golgi apparatus, and endoplasmic reticulum, which are clustered around the nucleus; large fluid filled vacuoles containing steroids, lipids, and proteins also accumulate $(12,13)$. The granulosa cell expands and reorganizes the contents of the cytoplasm, forming new organelles, particularly smooth endoplasmic reticulum (SER) for progesterone production (13). The SER and mitochondria are assembled in close association with the nucleus $(8,13)$. The mitochondria and large, round, lipid droplets are closely associated with the SER, all of which have substantially increased in number, and cluster around the nucleus to increase efficiency of steroid synthesis (Figure 2) (8).

During luteinization, granulosa cells form irregular microvilli and tight junctions between the cells, whereas in an apoptotic granulosa cell, the cell membrane disintegrates and spaces form (12). The apoptotic granulosa cell continues to produce steroids in large antral follicles until complete mitochondrial breakdown occurs (16).

\section{GRANULOSA CELL APOPTOSIS: THREE PHENOTYPES, THEIR INITIATION AND REGULATION}

Atresia of ovarian follicles can be divided into three phenotypes, each with different mechanisms of initiation and regulation, but all involving granulosa cell apoptosis (17). The first, so-called "antral atresia", affects the middle prolific layers of granulosa cells, with apoptosis progressing toward the antrum. The second, "basal atresia", occurs in the granulosa cells closest to the basal lamina of very small antral follicles. The cells prematurely luteinize and begin to produce progesterone; however, they do not complete luteinization, with subsequent cell death (17). A third form of apoptosis in the preovulatory follicles is referred to as "terminal differentiation apoptosis" and is similar to epidermal skin cells sloughing off $(10,18)$. The granulosa cells that are sloughed off from the antral surface form globules that aggregate and float into the antral fluid (10). The globules average $40 \mu \mathrm{m}$ in diameter and stain positively for propidium iodide (PI), which indicates that their cell membranes are compromised. However, the DNA is not fragmented, being of high molecular weight, and has a negative DNA fragmentation laddering result for the TUNEL (terminal deoxy-UPT nick end-labeling) assay. The majority of cell death in the membrana granulosa is via "antral atresia." Apoptotic bodies and cytoplasmic blebbing are typical of antral apoptosis, whereas apoptotic cells in the middle or basement section of the granulosa membrana are commonly engulfed by neighboring healthy granulosa cells and/or infiltrating macrophages. There are three main areas of apoptosis inducement; growth factors, death receptors and cell damage. Apoptosis can occur at any stage of the development of the follicle. In small follicles the granulosa cells are compact with large round nuclei. As the follicle matures the predominantly estrogen producing granulosa differentiates steroidogenically, increasing the volume of mitochondria and SER. Apoptosis at this stage of development would similarly result in condensation of the nucleic contents and clustering of the organelles around the nucleus. In the late stages of apoptosis, cell membranes are broken down and the contents compartmentalize into apoptotic bodies.

\section{MAJOR APOPTOSIS SIGNALING PATHWAYS IN THE OVARIAN FOLLICLE}

There are three major signaling pathways for the development of apoptosis in granulosa cells (19). The first is growth factorinduced high levels of cAMP through granzyme B; the second affects mitochondrial function via the Bcl2 family member activation; and the third utilizes tumor necrosis factor alpha $(\mathrm{TNF} \alpha)$ and Fas ligand (FasL)-Fas and other death receptors; all of which result in caspase-induced DNA fragmentation (Figure 3). In the ovary, granzyme B is stimulated by gonadotrophins and forskolin to bypass the mitochondria to preserve their function in the early stages of apoptosis, even though DNA fragmentation and nuclear collapse may have occurred (16).

Apoptosis can also be initiated by a number of extrinsic factors that may damage the cell such as DNA damage and oxidative 


\section{Granulosa cell Characterisation from Follicular to Luteal Stage}

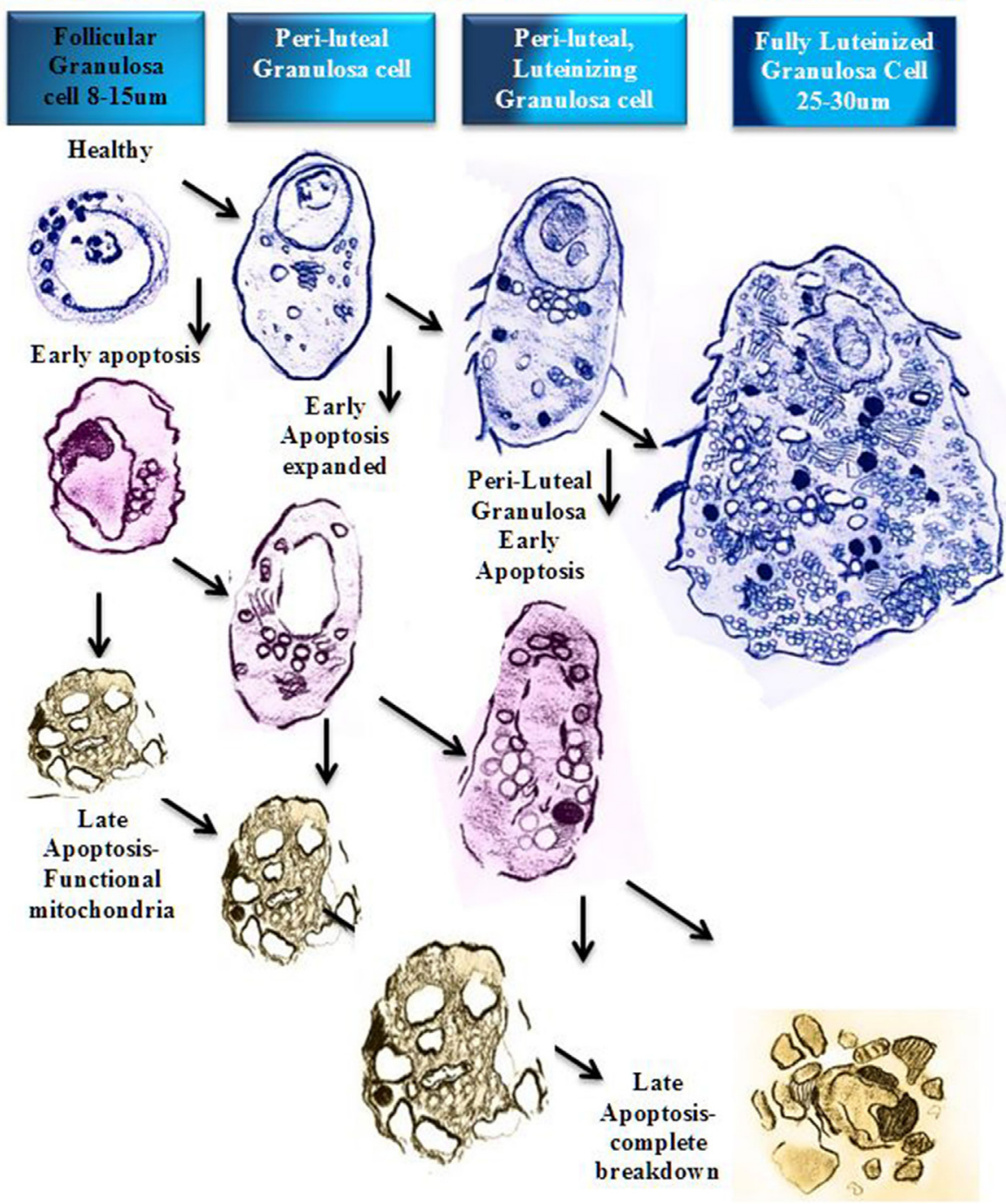

FIGURE 2 | Schematic diagram of granulosa cell characterization from follicular to luteal phase. In a stage-dependent progression, the granulosa differentiates from a compact 8-15 $\mu \mathrm{m}$ cell with a large round nucleus and relatively small cytoplasm (12). The cytoplasm contains mitochondria, rough endoplasmic reticulum, Golgi apparatus, lipid droplets, and many other organelles (14). As the granulosa cell matures, the organelles proliferate and the cytoplasm expands to accommodate new steroidogenic capacity. A fully luteinized granulosa cell, 25-30 $\mu \mathrm{m}$, contains a large volume of mitochondria, steroid filled lipid droplets, and smooth/rough endoplasmic reticulum, and has the capacity to produce progesterone directly (8). At any stage of follicular growth the granulosa cell can undergo apoptosis. Early apoptosis is characterized by collapse of the cell membranes and condensation of the chromatin, which often polarizes in the nucleus with the organelles clustered adjacent (15). Early apoptosis in a granulosa cell with an expanded cytoplasm is similarly changed with a greater volume of organelles clustered around a collapsing nucleus. Late stages of apoptosis end with compartmentalization of organelles into blebs and extrusion of apoptotic bodies that may contain nucleic matter.

stress, which activate p53-specific signaling pathways to trigger apoptotic mechanisms $(8,19,33)$.

Conversely, many growth factors [such as insulin-like growth factor (IGF), epidermal growth factor (EGF), and fibroblast growth factor (FGF)] as well as gonadotrophins (FSH and LH) are antiapoptotic, which creates a microenvironment that ensures survival.

Estrogen and progesterone are the main antiapoptotic factors along with FSH, LH, EGF, IGF, FGF, prolactin, laminin, leptin, and glucocorticoids. The steroid producing capacity of a follicle is reflected in the hormone levels within serum and follicular fluid from the antral cavity of the follicle under the influence of steroidogenic acute regulatory protein (StAR) (34). The steroids produced by the theca and granulosa cells provide an antiapoptotic effect in a stage-specific manner during folliculogenesis.

After dominant follicle selection, the theca cell mitochondria convert cholesterol to pregnenolone by cytochrome P450 sidechain cleavage enzyme, mediated by StAR. The pregnenolone is transported out of the mitochondria and converted to 


\section{Growth Factors}

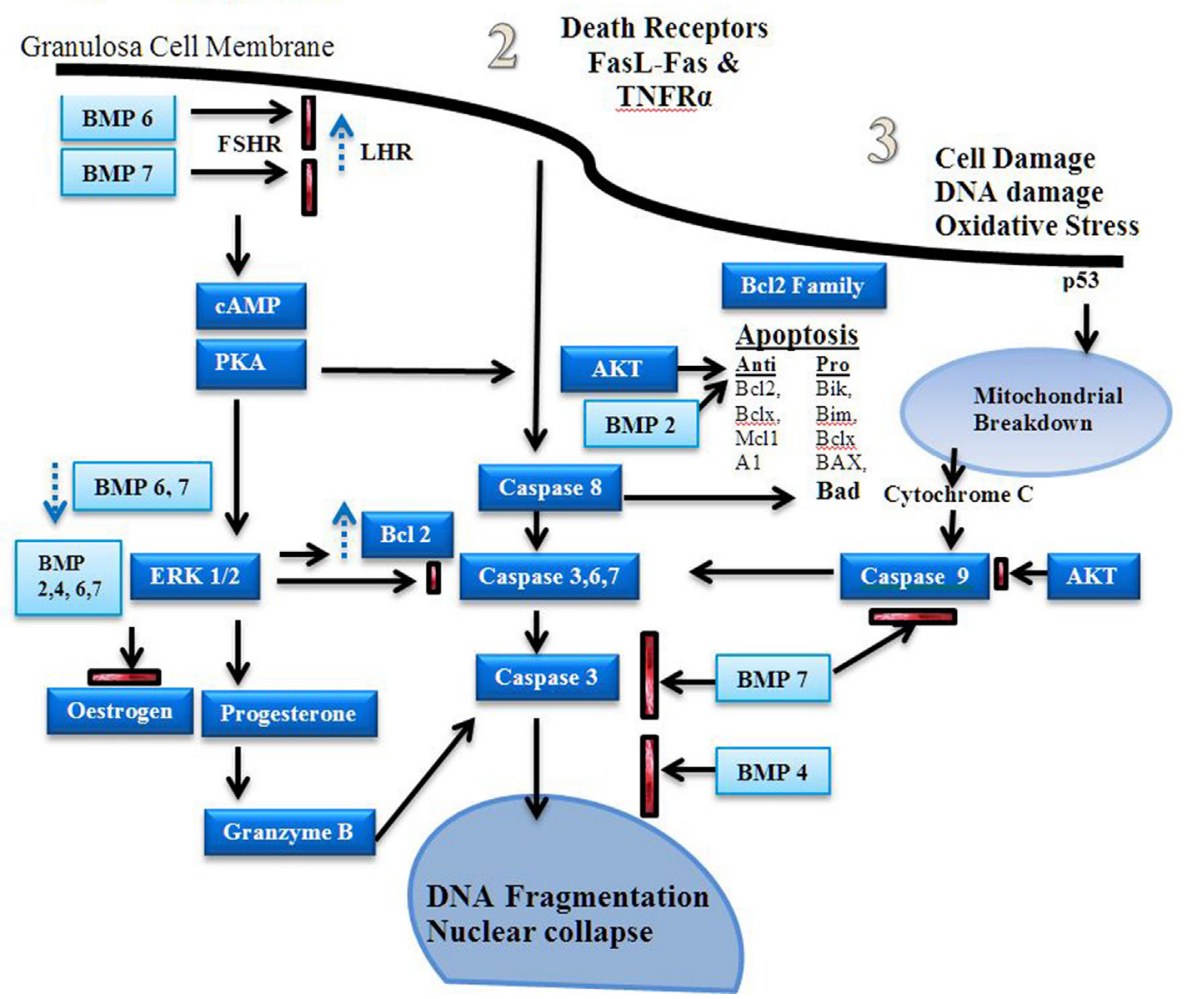

FIGURE 3 | Apoptosis signaling pathways. Estrogen is a major driver of follicular growth and its effects results in inhibition of apoptosis. There are three main areas of apoptosis inducement: 1. growth factors, 2. death receptors, and 3. cell damage (20). Before antral cavity formation ovarian follicle androgens increase the receptor of follicle stimulating hormone (FSH) expression and high levels of BMPR1B activity, possibly via BMP6 and 7, suppress LHR expression (21). Antiapoptotic FSH induced cAMP-PKA promote ERK1/2 signaling, which increases Bcl-2 and promotes estrogen production in favor of progesterone synthesis (22-24). The bone morphogenetic proteins (BMPs) 2, 4, 6, and 7 inhibit progesterone synthesis, which reduces caspase 3 , 6, and 7 production during the follicular phase (25). Dysregulation of the BMPs induces granzyme B synthesis leading to increased DNA fragmentation (16). Fas ligand (FasL) and TNFR activity induces caspase 8 induced DNA fragmentation (26). BMP 7 inhibits caspase 3 activity. Estrogen via the estrogen receptor has also been shown to reduce FasL activity $(27,28)$. Stress induced apoptosis via p53 causes mitochondrial breakdown via caspase 9 (29). Mitochondrial apoptosis is dependent on the ratio of pro and antiapoptotic factors of the Bcl-2 family (30). The Akt signaling pathway promotes antiapoptotic activity and is influenced by estrogen and growth factor-induced cAMP-PKA activity $(31,32)$.

progesterone by $3 \beta$-hydroxysteroid dehydrogen. The progesterone is then converted to androgens, predominantly androstenedione, dehydroepiandrosterone, and testosterone, and transported from the theca cell to the granulosa cell where it used to synthesize estrogen.

During the estrogen-driven proliferative phase of folliculogenesis, granulosa cell apoptosis is inhibited by antiapoptotic signaling pathways such as protein kinase $\mathrm{B}$ (Akt/PKB), extracellular signal-regulated kinase (ERK), EGF, and the BMPs. The Akt signaling pathway promotes antiapoptotic activity and is influenced by estrogen and growth factor induced cAMP-PKA activity. Estrogen directly inhibits FasL-induced apoptosis via the estrogen receptor, which activates the Akt-dependent pathway (20). In addition, the BMP ligands have been shown to inhibit apoptosis signaling down-stream of these signaling pathways in a number of studies $(25,35-38)$.

The LH surge-induced differentiation of the granulosa cell enables it to convert cholesterol to progesterone directly, and the levels rise substantially. At the time of ovulation the LH surge induces the granulosa cells to express progesterone receptors. The follicle undergoes progesterone-driven luteinization and enters the luteal phase, cell proliferation ceases, and high levels of progesterone inhibit apoptosis during corpus luteum formation (39).

\section{MITOCHONDRIAL PATHWAYS OF APOPTOSIS AND THE BMPs}

Apoptosis is induced via a change in the balance of proapoptotic factors versus antiapoptotic factors. In most cells of the body, mitochondrial apoptosis is the primary pathway involved in programmed cell death. However, in the ovary, early apoptosis begins in the nucleus of granulosa cells, bypassing the mitochondria until the later stage of apoptosis. The B-cell lymphoma 2 gene (Bcl-2) family consists of proapoptotic and antiapoptotic 
factors ( 40 known members) associated with the regulation of apoptosis via the mitochondria $(27,40)$.

Bone morphogenetic proteins have an inter-relationship with the proapoptotic factor Bax (a Bcl-2 derived prosurvival protein), and its ratio to antiapoptotic factors (Figure 3 ). $\mathrm{Bcl}-2$ opposes Bax and its destruction of the mitochondrial membranes. Bax is present from the resting primordial follicle onward; whereas $\mathrm{Bcl}-2$ is only present after primary to secondary transition, which may influence primordial follicle loss (41). BMP2, when overexpressed in renal tumors, signals via Smad 1, 5, and 8 (Smads, initially identified in drosophila, are signal transducers for receptors of the TGF-B superfamily), and increases GATA-4 expression, which inhibits Bax activity in the mitochondria (42). (The GATA transcription factor family are key mediators of sp hemopoietic progenitors.) In the mouse ovary, GATA-4 inhibits Bax-induced mitochondrial membrane permeabilization (41). Conversely, BMP2 induces apoptosis in bone by increasing caspase 3, 6, 7, and 9 expression (35), indicating a tissue-specific involvement of BMP2.

In the ovary BMP2 increases granulosal FSHRs in small follicles, and FSHR-mediated signaling is antiapoptotic in nature (43). This action occurs independently of granulosa cell proliferation induced by BMP2, highlighting the dual action capability of BMPs to inhibit and to induce cellular activity, and to induce differential responses during different stages of folliculogenesis.

In vitro culture of caprine granulosa cells with BMP2, 4, 6, and 7 reduces the percentage of DNA fragmentation (38). In the same study, FSHR silencing increased apoptosis. BMP4 neutralization in rodents causes an increase in apoptosis of the granulosa cells and the oocyte (37). BMP7 activated caspase 9 in granulosa cells; however, BMP4 and 7 had no effect on the levels of mitochondrial apoptotic factors, Bax and Bcl-x1 mRNA (25). Furthermore, BMP7 induced survivin and X-linked inhibitor of apoptosis protein to stimulate caspase 3 and 9 expression. BMP4, however, reduced factors downstream of caspase 3 that culminated in the reduction of apoptosis (Figure 3) (25).

\section{REGULATION OF BMPR1B AND FSHR AND THEIR INFLUENCE ON APOPTOSIS}

The BMP ligands are well established as regulators of granulosa cell proliferation in sheep $(25,44-48)$, cows $(25,49-52)$, and humans $(3,5,22,23,53-56)$. In addition, granulosa cell apoptosis increases dramatically around the time of dominant follicle selection when the ratio of androgen is greater than estrogen (49, 57-59). The start of follicle selection coincides with the down-regulation of granulosa cell BMPR1B and FSHR expression $(3,4,9)$.

In the transition from pre-antral to antral follicle, high levels of BMPs promote FSHR expression within the granulosa cells. The high levels of BMP6, 4, 7 (25), and BMP15 (60) concurrently sp suppress LHR expression in granulosa cells. During the subsequent follicle section process, the FSHR and BMPR1B expression is reduced along with the BMP ligands $4,6,7$, and 15 , and this may facilitate up-regulation of granulosa cell LHR expression (61). The follicles with granulosa cells expressing LHRs are able to continue to produce estrogens, and are recruited into the dominant cohort. FSHR is protective against apoptosis; therefore, as the FSHR level falls, apoptosis increases (4).

During continued growth of the selected dominant follicle, the estrogen levels rise to a critical level and trigger luteinization. Luteinization down-regulates the BMPR1B and the FSHRs in the ovulatory follicle. The reduction in FSHR and the cessation of proliferation momentarily reduces estrogen synthesis and the balance between proapoptotic and antiapoptotic factors. In older women, the dysregulation of granulosal FSHR and the BMPR1Bs would alter this balance and would be expected to change the apoptosis levels. An altered profile of BMPR1B expression in granulosa cells was also observed in young compared to older sheep $(47,62)$. Moreover, the BMPR1B mutation-induced reduction in apoptosis levels associated with the high ovulation rate in the Booroola sheep (47) was recently confirmed by the reduced GADD45A levels in the follicles of the Booroola sheep (62). (GADD45 alpha is a growth arrest and DNA-damage-inducible protein that is a gene marker for apoptosis.)

The cumulus granulosa cells surrounding the oocyte have reduced apoptosis levels compared to the mural granulosa cells $(2,63)$. The reduced apoptosis level is associated with the BMP ligand concentration gradient emanating from the oocyte (36). At the time of ovulation, luteinization expands the oocyte-cumulus complex, which closes the communication gap junctions between the oocyte and the cumulus cells. The disruption of the concentration gradient of BMPs results in an increase in the apoptosis level and reduced expression of LHR (64). Once luteinization has occurred, progesterone becomes the main antiapoptotic hormone.

\section{THE RELATIONSHIP BETWEEN APOPTOSIS AND OOCYTE QUALITY}

In IVF programs it has long been recognized that fewer than $10 \%$ of oocytes collected become live births (65); hence, in the 1990 s there was a concerted effort to find a marker for oocyte quality to better determine the chance of pregnancy. This led to investigations into the relationship between apoptosis and oocyte quality. Oocyte degeneration in the form of DNA fragmentation was linked to oocyte quality (66), and greater levels of DNA fragmentation were reported in the aged mouse oocyte. The level of granulosa cell apoptosis was increased in older IVF patients, similar to that observed in mice, and this was associated with a reduction in oocyte quality, fertilization, pregnancy, and live birth rate $(1,2,67-69)$.

\section{Earlier Studies and Apoptosis Theory}

The close proximity of the cumulus cells to the oocyte led to the investigation of cumulus cell apoptosis, and its relationship to fertility and oocyte quality. Lee et al. (70) found a strong association with fertility; however, conflicting results were also found (71). The level of cumulus cell apoptosis before the LH surge is reported to be less than $3 \%(2,72)$. After the acquisition of LHR (73) and expansion of the cumulus away from the oocyte, 
apoptosis levels increase in both the oocyte and in the cumulus cells (71).

However, the techniques initially employed for evaluating apoptosis were based on light microscopy assessment of pyknotic cell count or index. What was clear from these early studies was the variance in development of the non-ovulatory smaller follicles compared to the larger preovulatory follicles (7). Nakahara et al. (2) went on to examine the effect of the subject's age, and in contrast to other reports, they observed a reduced rate of granulosa cell apoptosis in the $40+$ years age group. This finding was overshadowed by emphasis on the greater level of granulosa cell apoptosis in patients with a "poor ovarian responsiveness" to gonadotrophin stimulation. For example, when ovarian reserve was indirectly equated to the number of oocytes collected $>12 \mathrm{~mm}$ in diameter, "independent of age," the granulosa cell apoptosis rate was significantly greater. This implies that women with low ovarian reserve, or more correctly poor "ovarian responsiveness" to IVF stimulation, had greater levels of granulosa cell apoptosis.

Apoptosis levels within granulosa cells were also greater in the women who did not become pregnant, and was associated with patients with a high FSH level at the start of a cycle (implying poor ovarian reserve). Interestingly, when adjusted for the confounders of age and number of oocytes retrieved, granulosa cell apoptosis was related to pregnancy outcome and not the ovarian reserve (1). The results were significantly confounded by many uncontrolled variables and the methodology used to evaluate apoptosis had limitations.

\section{Recent Studies and Revised Apoptosis Theory}

With the newer technique of flow cytometry, more granulosa cells could be examined ( 5,000 per follicle) and the white blood cell fraction could be selectively removed using CD45 magnetic beads for subtraction gating to improve the accuracy of identifying granulosa cells. However, the common practice of pooling the granulosa cells collected from a range of follicle sizes from each patient precluded the identification of follicle size-related differences. Other errors were introduced by selectively discarding follicles because they were contaminated with blood and by the spectral overlap between fluorescein isothiocyanate and PI that was not compensated for during flow cytometry $(1,68)$.

In the current era of research, it is possible to individually analyze the granulosa cells collected from a single follicle of a known size determined using ultrasonography (5). The granulosa cell population can be selectively gated to remove contaminating white blood cells using a CD45 monoclonal antibody. Common leukocyte antigen; 7AAD (far red DNA stain) can be used in place of PI to minimize spectral overlap or flow cytometric compensation can be performed.

The recent study of Regan et al. $(4,5)$ examined the relationship between ovarian reserve, granulosa cell receptor density and apoptosis during healthy human follicle development. The effect of the age of women undergoing the IVF protocol on granulosa cell apoptosis rate related to cell surface gonadotropin receptor and BMPRIB receptor expression. The study showed that the apoptotic rate of granulosa cells was higher in follicles during the two critical stages of dominant follicle selection and the preovulatory maturation stage of folliculogenesis in young women with better ovarian reserve, as determined by ultrasound-defined antral follicle counts (AFCs), compared to older women with a decreased AFC. The reduced apoptosis was associated with low levels of BMPR1B at the time of dominant follicle selection, whereas the lack of down-regulation of the BMPR1B, FSHR, and LHRs was associated with reduced granulosal apoptosis at the time of pre-ovulatory maturation $(3,4)$. The authors suggested that this result is a reflection of a poor mitogenic turnover rate of granulosa cells in healthy follicles in the older patients.

Notably, administration of gonadotropin-releasing hormone $(\mathrm{GnRH})$ was shown to increase apoptosis of both cumulus and mural granulosa cells. However, in clinical practice, the predictability of the LH surge by its suppression with $\mathrm{GnRH}$ has outlived the importance of the finding (74); however, only Hoechst staining was performed for apoptosis determination in that study. This change may have been helped by the finding from another study that the apoptosis level in granulosa cells was not correlated with oocyte quality or fertilization rate, which was determined by using a new technique of identifying very early apoptosis via Annexin V and PI and flow cytometry (75). In another study using PI and Bcl2 fluorescent staining of granulosa cells in patients with the same ovarian reserve and age, the fertilization rate was the same but the patients (women) who achieved a successful pregnancy had a reduced apoptotic index (76). However, variation was very wide in the non-pregnant group (13.61 \pm 9.26$)$. Internalization of the phospholipid membrane (Annexin V assay) occurs after the caspase proteolytic cascade, but before DNA condensation and fragmentation (11). Unfortunately, unintentionally induced apoptosis by centrifuging cells at $>300 \mathrm{~g}$ would limit the value of some studies $(67,74)$. In the study of Lee et al. (70), cumulus cell apoptosis was found to be greater in the $40+$ years age group, corresponding to a poorer fertilization rate; however, only 200 cumulus cells were counted per cumulus-oocyte complex, and only four patients were in the older age groups.

As new techniques were developed, and their sensitivity increased, the granulosa caspase activity was also analyzed (71, 76-79). Yuan et al. (71) found no difference in TUNEL staining and caspase activity until the LH surge, whereas caspase activity for the combined caspases 1-9 was present before the LH surge but then disappeared after the LH surge (71). In a recent study, the same technique of counting pyknotic cells found that the level of apoptosis was reduced in patients who became pregnant (80). The finding was supported by qPCR data of a greater level of caspase 3 in the non-pregnant group. Although the results appear robust, an undisclosed number of follicles were sampled (between 1 and 4 per patient), and were not necessarily the corresponding follicle that produced the pregnancy. To confound the finding further, two embryos were transferred per patient; therefore, the outcome of the fate for each follicle, pregnant or not, was unclear.

At this time, the mechanisms of apoptosis were being investigated to determine whether various factors were proapoptotic 
or antiapoptotic (81). Whole ovary investigations also took place and revealed the level of DNA fragmentation (TUNEL assay) and caspase 3 activity to be undetectable in adult primordial, primary, and secondary follicles $(59,78,82)$, whereas high levels of caspase-dependent apoptosis were recorded in antral follicles. However, in pre-ovulatory follicles, apoptosis was again rarely found (59). This change in apoptosis corresponds to the two critical times of FSHR down-regulation and LHR acquisition during dominant follicle selection; and later during pre-ovulatory down-regulation of LHR, FSHR, and BMPR1B $(3,5)$.

Early research by Sadraie et al. (67), reported that young patients produced more oocytes that were mature compared to the older age groups, which is consistent with the recently reported lack of down-regulation of BMPR1B, FSHR, and LHR, and final maturation of the follicle in older women (3-5). However, Jancar et al. (83), found no effect of granulosa cell apoptosis on fertilization rate or blastocyst development. Even though CD45-coated beads were used to purify the granulosa cells, they were pooled from multiple follicles. Moreover, the cells were centrifuged at $400 \mathrm{~g}$, which is known to induce apoptosis. These factors may limit the significance of this study as well as a similar study examining granulosa cells from pooled follicles, where cells were also centrifuged at $400 \mathrm{~g}(84)$.

In older patients, the follicular levels of oxidative stress were increased, which can be associated with reduced oocyte quality (29). However, both the embryo and the oocyte produce reactive oxygen species (ROS) as a normal part of metabolism, and the production of the ROS may reflect other changes to the ovarian environment that are associated with aging and not necessarily a result of changed apoptosis levels (29, 70, 85-88).

Recently, in human fetal whole ovaries, granulosa cells from primordial follicles were reported to be positive for caspase 3 and DNA fragmentation (89). This limited semi-quantitative study also reported high levels of BAX in primordial follicles and $\mathrm{Bcl} 2$ in secondary follicles. However, the level of caspase dependent apoptosis was not commensurate with the expected loss of primordial follicles before birth or postnatally $(89,90)$. The inconsistent low levels of apoptosis indicate that other forms of caspase-independent cell death are in operation.

Several new proposals have surfaced in relation to the mechanisms of programed cell death that do not have features

\section{REFERENCES}

1. Oosterhuis GJ, Michgelsen HW, Lambalk CB, Schoemaker J, Vermes I. Apoptotic cell death in human granulosa-lutein cells: a possible indicator of in vitro fertilization outcome. Fertil Steril (1998) 70:747-9. doi:10.1016/ S0015-0282(98)00266-0

2. Nakahara K, Saito H, Saito T, Ito M, Ohta N, Sakai N, et al. Incidence of apoptotic bodies in membrana granulosa of the patients participating in an in vitro fertilization program. Fertil Steril (1997) 67:302-8. doi:10.1016/ S0015-0282(97)81915-2

3. Regan SLP, Knight PG, Yovich J, Stanger J, Leung Y, Arfuso F, et al. Dysregulation of granulosal bone morphogenetic protein receptor $1 \mathrm{~B}$ density is associated with reduced ovarian reserve and the age-related decline in human fertility. Mol Cell Endocrinol (2016) 425:84-93. doi:10.1016/j. mce.2016.01.016 typically associated with apoptosis. These include autophagy (91), self-sacrifice to provide nutrients for neighboring follicles (92) and neuronal-endocrine induced apoptosis via the endoplasmic reticulum (93). Clearly, there are still many unanswered questions associated with the mechanism of cell death in the follicle.

\section{CONCLUSION}

The complex control of folliculogenesis, ovulation, and the luteal phase of follicle development relies on the balance of proapoptotic and antiapoptotic factors to regulate cell survival. Apoptosis in the granulosa cell is predominantly via caspase-dependent signaling pathways, and the majority of apoptosis results in terminal differentiation of the granulosa cell at the antral surface of the follicle. The type of apoptosis and the signaling pathway depends on the stage of development of the follicle and the origin of the intrinsic or extrinsic trigger. A large volume of granulosa cell apoptosis within the granulosa membrana leads to death of the follicle.

Optimal receptor expression during folliculogenesis ensures maximum estrogen synthesis, which is essential for follicle survival. Cessation of estrogen driven-proliferation leads to ovulation, which imposes a new regulatory paradigm. The progesterone dominated luteal phase is also regulated by receptor expression to promote cell survival and corpora lutea function.

Using the techniques available at this time, it is apparent that apoptosis levels of the granulosa cells are reflective of the proliferative stage of the follicle rather than a predictor of oocyte health. Apoptosis is not used as a marker in the clinical setting because of its poor predictive capability regarding oocyte quality and ensuing pregnancy rate. Recent studies challenge the longheld view that increased granulosa cell apoptosis is typical of older patients and is related to oocyte quality. Rather, granulosa cell apoptosis appears to be an integral part of normal follicle development and reflects the mitogenic growth of the follicle that varies in a stage-dependant manner.

\section{AUTHOR CONTRIBUTIONS}

SR wrote the first draft of the manuscript and the final version of the article. PK, JY, YL, FA, and AD contributed to the draft of the manuscript, and critically revised the manuscript.

4. Regan SLP, Knight PG, Yovich JL, Stanger JD, Leung Y, Arfuso F, et al. The effect of ovarian reserve and receptor signalling on granulosa cell apoptosis during human follicle development. Mol Cell Endocrinol (2017). doi:10.1016/j. mce.2017.11.002

5. Regan SLP, Knight PG, Yovich JL, Stanger JD, Leung Y, Arfuso F, et al. Infertility and ovarian follicle reserve depletion are associated with dysregulation of the FSH and LH receptor density in human antral follicles. Mol Cell Endocrinol (2017) 446:40-51. doi:10.1016/j.mce.2017.02.007

6. Bonfoco E, Krainc D, Ankarcrona M, Nicotera P, Lipton SA. Apoptosis and necrosis: two distinct events induced, respectively, by mild and intense insults with N-methyl-D-aspartate or nitric oxide/superoxide in cortical cell cultures. Proc Natl Acad Sci U S A (1995) 92:7162-6. doi:10.1073/pnas.92.16.7162

7. Bomsel-Helmreich O, Gougeon A, Thebault A, Saltarelli D, Milgrom E, Frydman R, et al. Healthy and atretic human follicles in the preovulatory phase: differences in evolution of follicular morphology and steroid content 
of follicular fluid. J Clin Endocrinol Metab (1979) 48:686-94. doi:10.1210/ jcem-48-4-686

8. Nottola SA, Heyn R, Camboni A, Correr S, Macchiarelli G. Ultrastructural characteristics of human granulosa cells in a coculture system for in vitro fertilization. Microsc Res Tech (2006) 69:508-16. doi:10.1002/jemt.20309

9. Tilly JL, Kowalski KI, Schomberg DW, Hsueh AJ. Apoptosis in atretic ovarian follicles is associated with selective decreases in messenger ribonucleic acid transcripts for gonadotropin receptors and cytochrome P450 aromatase. Endocrinology (1992) 131:1670-6. doi:10.1210/endo.131.4.1396312

10. Van Wezel IL, Dharmarajan AM, Lavranos TC, Rodgers RJ. Evidence for alternative pathways of granulosa cell death in healthy and slightly atretic bovine antral follicles. Endocrinology (1999) 140:2602-12. doi:10.1210/endo. 140.6 .6758

11. Demchenko A. Beyond annexin V: fluorescence response of cellular membranes to apoptosis. Cytotechnology (2013) 65:157-72. doi:10.1007/ s10616-012-9481-y

12. Guraya S. Morphology, histochemistry, and biochemistry of human ovarian compartments and steroid hormone synthesis. Physiol Rev (1971) 4:786-807.

13. Motta PM. Electron microscope study on the human lutein cell with special reference to its secretory activity. Z Zeltforsch Mikrosk Anat (1969) 98:233-45. doi:10.1007/BF00338327

14. Rotmensch S, Dor J, Furman A, Rudak E, Mashiach S, Amsterdam A. Ultrastructural characterization of human granulosa cells in stimulated cycles: correlation with oocyte fertilizability. Fertil Steril (1986) 45:671-9. doi:10.1016/S0015-0282(16)49340-4

15. Weakley BS. Electron microscopy of the oocyte and granulosa cells in the developing ovarian follicles of the golden hamster (Mesocricetus auratus). J Anat (1966) 100:503-34.

16. Amsterdam A, Sasson R, Keren Tal I, Aharoni D, Dantes A, Rimon E, et al. Alternative pathways of ovarian apoptosis: death for life. Biochem Pharmacol (2003) 66:1355-62. doi:10.1016/S0006-2952(03)00485-4

17. Irving-Rodgers HF, Krupa M, Rodgers RJ. Cholesterol side-chain cleavage cytochrome $\mathrm{P} 450$ and $3 \beta$-hydroxysteroid dehydrogenase expression and the concentrations of steroid hormones in the follicular fluids of different phenotypes of healthy and atretic bovine ovarian follicles. Biol Reprod (2003) 69:2022-8. doi:10.1095/biolreprod.103.017442

18. van Wezel IL, Rodgers RJ, Krupa M. Development of the membrana granulosa of bovine antral follicles: structure, location of mitosis and pyknosis, and immunolocalization of involucrin and vimentin. Reprod Fertil Dev (1999) 11:37-48. doi:10.1071/RD98069

19. Shen M, Liu Z, Li B, Teng Y, Zhang J, Tang Y, et al. Involvement of FoxO1 in the effects of follicle-stimulating hormone on inhibition of apoptosis in mouse granulosa cells. Cell Death Dis (2014) 5:e1475. doi:10.1038/cddis. 2014.400

20. Quirk SM, Cowan RG, Harman RM. The susceptibility of granulosa cells to apoptosis is influenced by oestradiol and the cell cycle. J Endocrinol (2006) 189:441-53. doi:10.1677/joe.1.06549

21. Rice S, Ojha K, Whitehead S, Mason H. Stage-specific expression of androgen receptor, follicle-stimulating hormone receptor, and anti-Müllerian hormone type II receptor in single, isolated, human preantral follicles: relevance to polycystic ovaries. J Clin Endocrinol Metab (2007) 92:1034-40. doi:10.1210/ jc. 2006-1697

22. Shi J, Yoshino O, Osuga Y, Koga K, Hirota Y, Hirata T, et al. Bone morphogenetic protein- 6 stimulates gene expression of follicle-stimulating hormone receptor, inhibin/activin beta subunits, and anti-Müllerian hormone in human granulosa cells. Fertil Steril (2009) 92:1794-8. doi:10.1016/j. fertnstert.2009.05.004

23. Shi J, Yoshino O, Osuga Y, Nishii O, Yano T, Taketani Y. Bone morphogenetic protein 7 (BMP-7) increases the expression of follicle-stimulating hormone (FSH) receptor in human granulosa cells. Fertil Steril (2010) 93:1273-9. doi:10.1016/j.fertnstert.2008.11.014

24. Shimasaki S, Moore R, Otsuka F, Erickson G. The bone morphogenetic protein system in mammalian reproduction. Endocr Rev (2004) 25:72-101. doi:10.1210/er.2003-0007

25. Kayamori T, Kosaka N, Miyamoto A, Shimizu T. The differential pathways of bone morphogenetic protein (BMP)- 4 and -7 in the suppression of the bovine granulosa cell apoptosis. Mol Cell Biochem (2009) 323:161-8. doi:10.1007/ s11010-008-9976-1
26. Quirk SM, Harman RM, Cowan RG. Regulation of Fas antigen (Fas, CD95)mediated apoptosis of bovine granulosa cells by serum and growth factors. Biol Reprod (2000) 63:1278-84. doi:10.1095/biolreprod63.5.1278

27. Qiu M, Liu J, Han C, Wu B, Yang Z, Su F, et al. The influence of ovarian stromal/theca cells during in vitro culture on steroidogenesis, proliferation and apoptosis of granulosa cells derived from the goat ovary. Reprod Domest Anim (2014) 49:170-6. doi:10.1111/rda.12256

28. Rosenfeld C, Wagner J, Roberts R, Lubahn D. Intraovarian actions of oestrogen. Reproduction (2001) 122:215-26. doi:10.1530/rep.0.1220215

29. Li YP, Liu J, Zhang JM, Liu NH, Liu DE, Chen XH. Effect of oxidative stress and apoptosis in granulosa cells on the quality of oocytes and the outcome of in vitro fertilization and embryo transfer (IVF-ET). Fertil Steril (2008) 90:S336-7. doi:10.1016/j.fertnstert.2008.07.1625

30. Perez GI, Jurisicova A, Wise L, Lipina T, Kanisek M, Bechard A, et al. Absence of the proapoptotic Bax protein extends fertility and alleviates age-related health complications in female mice. Proc Natl Acad Sci U S A (2007) 104:5229-34. doi:10.1073/pnas.0608557104

31. Ryan K, Glister C, Lonergan P, Martin F, Knight P, Evans A. Functional significance of the signal transduction pathways Akt and Erk in ovarian follicles: in vitro and in vivo studies in cattle and sheep. J Ovarian Res (2008) 1:2-2. doi:10.1186/1757-2215-1-2

32. Tepekoy F, Akkoyunlu G. The effect of FSH and activin A on Akt and MAPK1/3 phosphorylation in cultured bovine ovarian cortical strips. JOvarian Res (2016) 9:13. doi:10.1186/s13048-016-0222-2

33. Matsuda F, Inoue N, Manabe N, Ohkura S. Follicular growth and atresia in mammalian ovaries: regulation by survival and death of granulosa cells. J Reprod Dev (2012) 58:44-50. doi:10.1262/jrd.2011-012

34. Miller WL, Auchus RJ. The molecular biology, biochemistry, and physiology of human steroidogenesis and its disorders. Endocr Rev (2011) 32(1):81-151. doi:10.1210/er.2010-0013

35. Haÿ E, Lemonnier J, Fromigué O, Guénou H, Marie PJ. Bone morphogenetic protein receptor IB signaling mediates apoptosis independently of differentiation in osteoblastic cells. J Biol Chem (2004) 279:1650-8. doi:10.1074/jbc. M300969200

36. Hussein T, Froiland D, Amato F, Thompson J, Gilchrist R. Oocytes prevent cumulus cell apoptosis by maintaining a morphogenic paracrine gradient of bone morphogenetic proteins. JCell Sci (2005) 118:5257-68. doi:10.1242/ jcs. 02644

37. Nilsson EE, Skinner MK. Bone morphogenetic protein-4 acts as an ovarian follicle survival factor and promotes primordial follicle development. Biol Reprod (2003) 69:1265-72. doi:10.1095/biolreprod.103.018671

38. Zhu G, YCui Y, Wang Q, Kang Y, Lv Y, Wang J, et al. Bone morphogenetic proteins (BMP) 2,4,6, and 7 affect ovarian follicular development through regulation of follicle-stimulating hormone receptor (FSHR) and lutenizing hormone (LHR) expression in goat granulosa cells. J Cell Biol Genet (2013) 3(1):14-21. doi:10.5897/JCBG12.004

39. Quirk SM, Cowan RG, Harman RM. Progesterone receptor and the cell cycle modulate apoptosis in granulosa cells. Endocrinology (2004) 145:5033-43. doi:10.1210/en.2004-0140

40. Tamm C, Robertson JD, Sleeper E, Enoksson M, Emgård M, Orrenius S, et al. Differential regulation of the mitochondrial and death receptor pathways in neural stem cells. Eur J Neurosci (2004) 19:2613-21. doi:10.1111/j. 0953-816X.2004.03391.x

41. Vaskivuo TE, Tapanainen JS. Apoptosis in the human ovary. Reprod Biomed Online (2003) 6:24-35. doi:10.1016/S1472-6483(10)62052-4

42. Mitsui Y, Hirata H, Arichi N, Hiraki M, Yasumoto H, Chang I, et al. Inactivation of bone morphogenetic protein 2 may predict clinical outcome and poor overall survival for renal cell carcinoma through epigenetic pathways. Oncotarget (2015) 6:9577-91. doi:10.18632/oncotarget.3445

43. Shi J, Yoshino O, Osuga Y, Koga K, Hirota Y, Nose E, et al. Bone morphogenetic protein-2 (BMP-2) increases gene expression of FSH receptor and aromatase and decreases gene expression of LH receptor and StAR in human granulosa cells. Am J Reprod Immunol (2011) 65:421-7. doi:10.1111/j.16000897.2010.00917.x

44. Chen AQ, Yu S, Wang Z, Xu Z, Yang Z. Stage-specific expression of bone morphogenetic protein type I and type II receptor genes: effects of follicle-stimulating hormone on ovine antral follicles. Anim Reprod Sci (2008) 111:391-9. doi:10.1016/j.anireprosci.2008.03.011 
45. Fabre S, Pierre A, Pisselet C, Mulsant P, Lecerf F, Pohl J, et al. The Booroola mutation in sheep is associated with an alteration of the bone morphogenetic protein receptor-IB functionality. JEndocrinol (2003) 177:435-44. doi:10.1677/joe.0.1770435

46. Mulsant P, Lecerf F, Fabre S, Schibler L, Monget P, Lanneluc I, et al. Mutation in bone morphogenetic protein receptor-IB is associated with increased ovulation rate in Booroola Mérino ewes. Proc Natl Acad Sci U S A (2001) 98:5104-9. doi:10.1073/pnas.091577598

47. Regan SLP, McFarlane JR, O’Shea T, Andronicos N, Arfuso F, Dharmarajan A, et al. Flow cytometric analysis of FSHR, BMRR1B, LHR and apoptosis in granulosa cells and ovulation rate in merino sheep. Reproduction (2015) 150:151-63. doi:10.1530/REP-14-0581

48. Young JM, Juengel JL, Dodds KG, Laird M, Dearden PK, McNeilly AS, et al. The activin receptor-like kinase 6 Booroola mutation enhances suppressive effects of bone morphogenetic protein 2 (BMP2), BMP4, BMP6 and growth and differentiation factor-9 on FSH release from ovine primary pituitary cell cultures. J Endocrinol (2008) 196:251-61. doi:10.1677/ JOE-07-0148

49. Austin EJ, Mihm M, Evans ACO, Knight PG, Ireland JLH, Ireland JJ, et al. Alterations in intrafollicular regulatory factors and apoptosis during selection of follicles in the first follicular wave of the bovine estrous cycle. Biol Reprod (2001) 64:839-48. doi:10.1095/biolreprod64.3.839

50. Glister C, Kemp CF, Knight PG. Bone morphogenetic protein (BMP) ligands and receptors in bovine ovarian follicle cells: actions of BMP-4, -6 and -7 on granulosa cells and differential modulation of Smad-1 phosphorylation by follistatin. Reproduction (2004) 127:239-54. doi:10.1530/rep.1.00090

51. Kayani AR, Glister C, Knight PG. Evidence for an inhibitory role of bone morphogenetic protein(s) in the follicular-luteal transition in cattle. Reproduction (2009) 137:67-78. doi:10.1530/REP-08-0198

52. Knight PG, Glister C. Local roles of TGF- $\beta$ superfamily members in the control of ovarian follicle development. Anim Reprod Sci (2003) 78:165-83. doi:10.1016/S0378-4320(03)00089-7

53. Di Pasquale E, Rossetti R, Marozzi A, Bodega B, Borgato S, Cavallo L, et al. Identification of new variants of human BMP15 gene in a large cohort of women with premature ovarian failure. JClin Endocrinol Metab (2006) 91:1976-9. doi:10.1210/jc.2005-2650

54. Dooley CA, Attia GR, Rainey WE, Moore DR, Carr BR. Bone morphogenetic protein inhibits ovarian androgen production. J Clin Endocrinol Metab (2000) 85:3331-7. doi:10.1210/jcem.85.9.6835

55. Shi J, Yoshino O, Osuga Y, Akiyama I, Harada M, Koga K, et al. Growth differentiation factor 3 is induced by bone morphogenetic protein 6 (BMP6) and BMP-7 and increases luteinizing hormone receptor messenger RNA expression in human granulosa cells. Fertil Steril (2012) 97:979-83. doi:10.1016/j.fertnstert.2012.01.100

56. Shimasaki S, Zachow RJ, Li D, Kim H, Iemura S-i, Ueno N, et al. A functional bone morphogenetic protein system in the ovary. Proc Natl Acad Sci U S A (1999) 96:7282-7. doi:10.1073/pnas.96.13.7282

57. Bao B, Garverick HA, Smith GW, Smith MF, Salfen BE, Youngquist RS. Changes in messenger ribonucleic acid encoding luteinizing hormone receptor, cytochrome $\mathrm{P} 450$-side chain cleavage, and aromatase are associated with recruitment and selection of bovine ovarian follicles. Biol Reprod (1997) 56:1158-68. doi:10.1095/biolreprod56.5.1158

58. Sen A, Prizant H, Light A, Biswas A, Hayes E, Lee H-J, et al. Androgens regulate ovarian follicular development by increasing follicle stimulating hormone receptor and microRNA-125b expression. Proc Natl Acad Sci U S A (2014) 111(8):3008-13. doi:10.1073/pnas.1318978111

59. Yuan W, Giudice L. Programmed cell death in human ovary is a function of follicle and corpus luteum status. J Clin Endocrinol Metab (1997) 82:3148-55. doi:10.1210/jc.82.9.3148

60. Feary E, Juengel J, Smith P, French M, O’Connell A, Lawrence S, et al. Patterns of expression of messenger RNAs encoding GDF9, BMP15, TGFBR1, BMPR1B, and BMPR2 during follicular development and characterization of ovarian follicular populations in ewes carrying the Woodlands FecX2W mutation. Biol Reprod (2007) 77:990-8. doi:10.1095/biolreprod.107.062752

61. Regan S, Knight PG, Yovich JL, Yeung Y, Arfuso F, Dharmarajan A. The Involvement of bone morphogenetic proteins (BMP) in the regulation of ovarian function. Vitamins and Hormones, Ovarian Cycle. Academic Press/ Elsevier (2018). 105 p.
62. Anthony E, Pierre A, di Clemente N, Picard J-Y, Jarrier P, Mansanet C, et al. Anti-Müllerian hormone regulation by the bone morphogenetic proteins in the sheep ovary: deciphering a direct regulatory pathway. Endocrinology (2015) 156:301-13. doi:10.1210/en.2014-1551

63. Ruvolo G, Bosco L, Pane A, Morici G, Cittadini E, Roccheri M. Lower apoptosis rate in human cumulus cells after administration of recombinant luteinizing hormone to women undergoing ovarian stimulation for in vitro fertilization procedures. Fertil Steril (2007) 87:542-6. doi:10.1016/j. fertnstert.2006.06.059

64. Shimada M, Nishibori M, Isobe N, Kawano N, Terada T. Luteinizing hormone receptor formation in cumulus cells surrounding porcine oocytes and its role during meiotic maturation of porcine oocytes. Biol Reprod (2003) 68:1142-9. doi:10.1095/biolreprod.102.010082

65. Stanger JD, Yovich JL. Follicle recruitment determines IVF productivity rate via the number of embryos frozen and subsequent transfers. Reprod Biomed Online (2013) 27:286-96. doi:10.1016/j.rbmo.2013.05.015

66. Fujino Y, Ozaki K, Yamamasu S, Ito F, Matsuoka I, Hayashi E, et al. Ovary and ovulation: DNA fragmentation of oocytes in aged mice. Hum Reprod (1996) 11:1480-3. doi:10.1093/oxfordjournals.humrep.a019421

67. Sadraie SH, Saito H, Kaneko T, Saito T, Hiroi M. Effects of aging on ovarian fecundity in terms of the incidence of apoptotic granulosa cells. J Assist Reprod Genet (2000) 17:168-73. doi:10.1023/A:1009422323306

68. Seifer D, Gardiner AC, Ferreira KA, Peluso JJ. Apoptosis as a function of ovarian reserve in women undergoing in vitro fertilization. Fertil Steril (1996) 66(4):593-8. doi:10.1016/S0015-0282(16)58573-2

69. Sifer C, Bénifla J-L, Bringuier A-F, Porcher R, Blanc-Layrac G, Madélénat P, et al. Could induced apoptosis of human granulosa cells predict in vitro fertilization-embryo transfer outcome? Eur J Obstet Gynecol Reprod Biol (2002) 103:150-3. doi:10.1016/S0301-2115(02)00043-X

70. Lee KS, Joo BS, Na YJ, Yoon MS, Choi OH, Kim WW. Clinical assisted reproduction: cumulus cells apoptosis as an indicator to predict the quality of oocytes and the outcome of IVF-ET. J Assist Reprod Genet (2001) 18:490-8. doi:10.1023/A:1011910125079

71. Yuan YQ, Van Soom A, Leroy JLMR, Dewulf J, Van Zeveren A, de Kruif A, et al. Apoptosis in cumulus cells, but not in oocytes, may influence bovine embryonic developmental competence. Theriogenology (2005) 63:2147-63. doi:10.1016/j.theriogenology.2004.09.054

72. Bencomo E, Pérez R, Arteaga M-F, Acosta E, Peña O, Lopez L, et al. Apoptosis of cultured granulosa-lutein cells is reduced by insulin-like growth factor I and may correlate with embryo fragmentation and pregnancy rate. Fertil Steril (2006) 85:474-80. doi:10.1016/j.fertnstert.2005.08.014

73. Maman E, Yung Y, Kedem A, Yerushalmi GM, Konopnicki S, Cohen B, et al. High expression of luteinizing hormone receptors messenger RNA by human cumulus granulosa cells is in correlation with decreased fertilization. Fertil Steril (2012) 97:592-8. doi:10.1016/j.fertnstert.2011.12.027

74. Kaneko T, Saito H, Takahashi T, Ohta N, Saito T, Hiroi M. Effects of controlled ovarian hyperstimulation on oocyte quality in terms of the incidence of apoptotic granulosa cells. J Assist Reprod Genet (2000) 17:580-5. doi:10.102 3/A:1009470206468

75. Clavero A, Castilla JA, Núñez AI, García-Peña ML, Maldonado V, Fontes J, et al. Apoptosis in human granulosa cells after induction of ovulation in women participating in an intracytoplasmic sperm injection program. Eur J Obstet Gynecol Reprod Biol (2003) 110:181-5. doi:10.1016/S03012115(03)00243-4

76. Suh CS, Jee BC, Choi YM, Kim JG, Lee JY, Moon SY, et al. Prognostic implication of apoptosis in human luteinized granulosa cells during IVF-ET. J Assist Reprod Genet (2002) 19:209-14. doi:10.1023/A:1015319617598

77. D’haeseleer M, Cocquyt G, Cruchten SV, Simoens P, Broeck WVD. Cellspecific localisation of apoptosis in the bovine ovary at different stages of the oestrous cycle. Theriogenology (2006) 65:757-72. doi:10.1016/j. theriogenology.2005.07.008

78. Glamočlija V, Vilović K, Saraga-Babić M, Baranović A, Sapunar D. Apoptosis and active caspase-3 expression in human granulosa cells. Fertil Steril (2005) 83:426-31. doi:10.1016/j.fertnstert.2004.06.075

79. Lai Q, Xiang W, Li Q, Zhang H, Li Y, Zhu G, et al. Oxidative stress in granulosa cells contributes to poor oocyte quality and IVF-ET outcomes in women with polycystic ovary syndrome. Front Med (2017). doi:10.1007/ s11684-017-0575-y 
80. Lin D, Ran J, Zhu S, Quan S, Ye B, Yu A, et al. Effect of GOLPH3 on cumulus granulosa cell apoptosis and ICSI pregnancy outcomes. Sci Rep (2017) 7:7863. doi:10.1038/s41598-017-08343-w

81. Sasson R, Amsterdam A. Stimulation of apoptosis in human granulosa cells from in vitro fertilization patients and its prevention by dexamethasone: involvement of cell contact and bcl-2 expression. J Clin Endocrinol Metab (2002) 87:3441-51. doi:10.1210/jcem.87.7.8676

82. Albamonte MI, Albamonte MS, Stella I, Zuccardi L, Vitullo AD. The infant and pubertal human ovary: Balbiani's body-associated VASA expression, immunohistochemical detection of apoptosis-related BCL2 and BAX proteins, and DNA fragmentation. Hum Reprod (2013) 28:698-706. doi:10.1093/humrep/des453

83. Jančar N, Kopitar AN, Ihan A, Klun IV, Bokal EV. Effect of apoptosis and reactive oxygen species production in human granulosa cells on oocyte fertilization and blastocyst development. J Assist Reprod Genet (2007) 24:91-7. doi:10.1007/s10815-006-9103-8

84. Giampietro F, Sancilio S, Tiboni GM, Rana RA, Di Pietro R. Levels of apoptosis in human granulosa cells seem to be comparable after therapy with a gonadotropin-releasing hormone agonist or antagonist. Fertil Steril (2006) 85:412-9. doi:10.1016/j.fertnstert.2005.08.020

85. Bausenwein J, Serke H, Eberle K, Hirrlinger J, Jogschies P, Hmeidan FA, et al. Elevated levels of oxidized low-density lipoprotein and of catalase activity in follicular fluid of obese women. Mol Hum Reprod (2010) 16:117-24. doi:10.1093/molehr/gap078

86. Carbone MC, Tatone C, Monache SD, Marci R, Caserta D, Colonna R, et al. Antioxidant enzymatic defences in human follicular fluid: characterization and age-dependent changes. Mol Hum Reprod (2003) 9:639-43. doi:10.1093/ molehr/gag090

87. Combelles CMH, Gupta S, Agarwal A. Could oxidative stress influence the in-vitro maturation of oocytes? Reprod Biomed Online (2009) 18:864-80. doi:10.1016/S1472-6483(10)60038-7

88. Wiener-Megnazi Z, Vardi L, Lissak A, Shnizer S, Zeev Reznick A, Ishai D, et al. Oxidative stress indices in follicular fluid as measured by the thermochemiluminescence assay correlate with outcome parameters in in vitro fertilization. Fertil Steril (2004) 82:1171-6. doi:10.1016/j.fertnstert.2004. 06.013

89. Poljicanin A, Vukusic Pusic T, Vukojevic K, Caric A, Vilovic K, Tomic S, et al. The expression patterns of pro-apoptotic and anti-apoptotic factors in human fetal and adult ovary. Acta Histochem (2013) 115:533-40. doi:10.1016/j. acthis.2012.11.009

90. Albamonte MS, Albamonte MI, Vitullo AD. Germ line apoptosis in the mature human ovary. J Med Res Sci (2012) 2:136-45.

91. Rodrigues P, Limback D, McGinnis LK, Plancha CE, Albertini DF. Multiple mechanisms of germ cell loss in the perinatal mouse ovary. Reproduction (2009) 137:709-20. doi:10.1530/REP-08-0203

92. Pepling ME, Spradling AC. Mouse ovarian germ cell cysts undergo programmed breakdown to form primordial follicles. Dev Biol (2001) 234:339-51 doi:10.1006/dbio.2001.0269

93. Levi-Ferber M, Salzberg Y, Safra M, Haviv-Chesner A, Bülow HE, HenisKorenblit S. It's all in your mind: determining germ cell fate by neuronal IRE-1 in C. elegans. PLoS Genet (2014) 10:e1004747. doi:10.1371/journal. pgen.1004747

Conflict of Interest Statement: The authors declare that the research was conducted in the absence of any commercial or financial relationships that could be construed as a potential conflict of interest.

Copyright (C) 2018 Regan, Knight, Yovich, Leung, Arfuso and Dharmarajan. This is an open-access article distributed under the terms of the Creative Commons Attribution License (CC BY). The use, distribution or reproduction in other forums is permitted, provided the original author(s) and the copyright owner are credited and that the original publication in this journal is cited, in accordance with accepted academic practice. No use, distribution or reproduction is permitted which does not comply with these terms. 